\title{
Absorption of Calcium in Premature Infants as Measured With a Stable Isotope ${ }^{46} \mathrm{Ca}$ Extrinsic Tag
}

\author{
RICHARD A. EHRENKRANZ, BARBARA A. ACKERMAN, CATHERINE M. NELLI, AND \\ MORTEZA JANGHORBANI \\ Departments of Pediatrics and Obstetrics and Gynecology, Yale University School of Medicine [R.A.E., C.M.N.]; \\ Department of Nursing, Yale-New Haven Hospital [B.A.A.], New Haven, Connecticut; and Nuclear Reactor \\ Laboratory, Massachusetts Institute of Technology, Cambridge, Massachusetts and Department of Pathology \\ (Nutrition) Boston University School of Medicine [M.J.], Boston, Massachusetts
}

\begin{abstract}
Absorption of dietary calcium was evaluated with the extrinsic tag approach and stable isotope methodology in growing premature infants. Fractional absorption of a bolus dose of ${ }^{46} \mathrm{Ca}$ was determined on 16 occasions in 13 premature infants (birth weight $1135 \pm \mathbf{4 0} \mathrm{g}$, gestational age $29.5 \pm 0.4 \mathrm{wk}$, mean $\pm \mathrm{SE}$ ) and was found to be $84.4 \pm 2.2 \%$. Fractional absorption of ${ }^{46} \mathrm{Ca}$ ranged between 65 and $97 \%$, and did not appear to be influenced by postnatal age, postconceptual age, body weight, or intake of preterm human milk, fortified preterm human milk, or premature formula. Therefore, if absorption of the ${ }^{46} \mathrm{Ca}$ dose reflects that of dietary calcium, about $80 \%$ of dietary calcium is absorbed. (Pediatr Res 19:178-184, 1985)
\end{abstract}

\section{Abbreviations}

PTHM, preterm human milk NBSCU, Newborn Special Care Unit able results due to several technical problems $(2,25)$. Therefore there is a need to acquire accurate data on true absorption of dietary calcium and the factors that modulate its absorption, and to distinguish between unabsorbed dietary calcium and that originating from endogenous secretions. In this study we have employed the extrinsic tag approach with stable isotope methodology (21) to compare absorption of dietary calcium in growing premature infants fed PTHM, fortified-PTHM, or a proprietary premature formula. This methodology is based on the use of naturally occurring, nonradioactive isotopes as tracers $(25$, 26). This method has been previously utilized by Barltrop et al. (7) to study calcium balance in premature infants fed one of three experimental formulas that varied widely in content of calcium and phosphorus, and by Ehrenkranz et al. (11) to investigate zinc absorption in the premature infants described herein. In addition, this methodology has been extensively employed in human adults for assessment of the dietary availability of calcium $(21)$, zinc $(23,27)$, copper $(36)$, iron $(22,23)$, and selenium $(19,24)$.

\section{MATERIALS AND METHODS}

Recommendations of dietary calcium requirements for growing premature infants have often been based on estimates of the rate of in utero calcium accumulation and on measurements of net calcium absorption and retention $(2,3,31,32,41)$. However, these recommendations may be difficult to achieve. Studies with premature infants, especially those weighing less than $1500 \mathrm{~g}$ at birth, have frequently suggested deficient skeletal mineralization when the infants have been fed human milk, mature or preterm, or some proprietary formulas $(2,31,34)$. In those cases, the intrauterine calcium accretion rate was not met because the low calcium content of human milk resulted in an absolute dietary deficiency of calcium, while the higher calcium contents of the formulas were poorly absorbed. However, several recent studies $(18,33,34)$ with formulas specifically designed to meet the nutritional needs of the growing premature infant have demonstrated net calcium absorption and retention at the in utero rate.

Unfortunately the metabolic balance methodology employed to assess calcium absorption and retention often produces vari-

Received June 8, 1984; accepted September 28, 1984.

Address correspondence and reprint requests to Dr. Richard Ehrenkranz, Department of Pediatrics, Yale University School of Medicine, 333 Cedar Street, New Haven, CT 06510.

Supported in part by grants from the Children's Clinical Research Center, (RR00125 NIH), the Charles H. Hood Foundation, Reactor Sharing Program Funds (USDOE Grant DE-FG02-80Er10770), and the Mead Johnson Nutritional Division.
Subjects. Eighteen appropriate for gestational age infants with birth weights less than or equal to $1350 \mathrm{~g}$ who were cared for in the NBSCU, Yale-New Haven Hospital because of prematurity were enrolled in this investigation at the time that enteral (nasogastric) feedings were initiated. Although each infant was stable, tolerating feedings, and was growing steadily at the time that the determination of calcium absorption was performed, 10 of them had had mild to moderate respiratory distress syndrome that required ventilatory assistance and 10 had been or were still being treated with theophylline or caffeine for apneic and/or bradycardic episodes. Determinations of calcium absorption were attempted on 23 occasions in these 18 infants. However, the data from only 16 of these studies in 13 infants will form the basis of this report. The remaining seven studies have not been included because of poor stool collections. Permission to include each infant in the study was obtained by informed consent of the parents. This protocol was approved by the Human Investigation Committee, Yale University School of Medicine, and the Committee On the Use of Humans as Experimental Subjects, Massachusetts Institute of Technology.

Relevant data for the 13 infants in whom 16 determinations of calcium absorption were successfully performed are listed in Table 1 . These 13 infants had a mean gestational age of $29.5 \pm$ $0.4 \mathrm{wk}$ (mean $\pm \mathrm{SE}$ ) and a mean birth weight of $1135 \pm 40 \mathrm{~g}$. Dietary assignment was related to parental preference and had 
Table 1. Study population

\begin{tabular}{|c|c|c|c|c|c|c|}
\hline \multirow[b]{2}{*}{ Infant } & \multicolumn{6}{|c|}{ At determination of calcium absorption } \\
\hline & $\begin{array}{l}\text { Gestational } \\
\text { age (wk) }\end{array}$ & $\begin{array}{l}\text { Birth wt } \\
\text { (g) }\end{array}$ & $\begin{array}{l}\text { Postnatal } \\
\text { age (days) }\end{array}$ & $\begin{array}{l}\text { Postconceptual } \\
\text { age (days) }\end{array}$ & $\begin{array}{l}\text { Body wt } \\
\text { (g) }\end{array}$ & $\begin{array}{l}\% \text { of }{ }^{46} \mathrm{Ca} \\
\text { absorption }\end{array}$ \\
\hline \multicolumn{7}{|l|}{ PTHM } \\
\hline BBVA & 30 & 1240 & 30 & 240 & 1455 & 86 \\
\hline $\operatorname{BBVB}(\mathrm{A})^{*}$ & 30 & 1350 & 26 & 236 & 1460 & 97 \\
\hline BBS & & & 30 & 240 & 1560 & 85 \\
\hline BGMB & 27 & 960 & 58 & 247 & 1450 & 92 \\
\hline \multirow[t]{2}{*}{ Mean \pm SE } & 29 & 860 & 30 & 233 & 1230 & 88 \\
\hline & $29.0 \pm 0.7$ & $1102 \pm 115$ & $34.8 \pm 5.9$ & $239 \pm 2$ & $1431 \pm 54$ & $89.6 \pm 2.2$ \\
\hline \multicolumn{7}{|c|}{ Fortified-PTHM } \\
\hline BBM & 32 & 1240 & 20 & 244 & 1560 & 74 \\
\hline BBTB & 31 & 1210 & 25 & 239 & 1690 & 96 \\
\hline BBW & 30 & 1200 & 20 & 230 & 1500 & 84 \\
\hline BBD & 29 & 1120 & 23 & 226 & 1530 & 69 \\
\hline Mean $\pm S E$ & $30.5 \pm 0.6$ & $1192 \pm 26$ & $22.0 \pm 1.2$ & $235 \pm 4$ & $1570 \pm 42$ & $80.8 \pm 6.0$ \\
\hline \multicolumn{7}{|c|}{ Premature formula } \\
\hline BGS & 29 & 1010 & 15 & 218 & 1100 & 78 \\
\hline \multirow[t]{2}{*}{$\mathrm{BBC}(\mathrm{B})^{*}$} & 28 & 1230 & 23 & 219 & 1300 & 86 \\
\hline & & & 37 & 233 & 1550 & 87 \\
\hline BBB & 30 & 1220 & 24 & 234 & 1480 & 85 \\
\hline BBP & 30 & 1160 & 23 & 233 & 1200 & 65 \\
\hline \multirow[t]{2}{*}{ BGSA $(\mathrm{C})^{*}$} & 29 & 960 & 26 & 229 & 1080 & 93 \\
\hline & & & 43 & 246 & 1520 & 85 \\
\hline Mean $\pm \mathrm{SE}$ & $29.2 \pm 0.4$ & $1116 \pm 55$ & $27.3 \pm 3.6$ & $230 \pm 3.6$ & $1318 \pm 75$ & $82.7 \pm 3.4$ \\
\hline
\end{tabular}

* Letter in parentheses refers to infant indicated in Figures.

$\mathrm{BB}$, baby boy; BG, baby girl.

been decided by the time that nasogastric feedings were initiated. Five infants whose mothers did not wish to provide them with expressed PTHM received a proprietary premature formula (Enfamil Premature Formula, Mead Johnson Nutritional Division, Evansville, IN). Each of the mothers of the other eight infants wished to provide her own infant(s) with expressed PTHM during his/her hospitalization in the NBSCU. These infants were randomly assigned to receive only their own mother's PTHM (four infants) or fortified-PTHM, a 1:1 (volume/volume) mixture of their own mother's PTHM and the proprietary premature formula (four infants). PTHM was expressed about four to six times per day, primarily with an electric breast pump (Egnell Electric Breast Pump, Egnell, Inc., Cary, IL), but also by hand and handpump. It was fed to the infants in the order in which it was expressed and was stored without pooling or pasteurization in plastic containers within a Human Milk Bank maintained in the NBSCU. If the milk could be fed to the infant within $48 \mathrm{~h}$ of collection, it was refrigerated at $4^{\circ} \mathrm{C}$. Otherwise, it was frozen $\left(-4^{\circ} \mathrm{C}\right)$ and gently thawed prior to each feeding.

All of the infants were managed according to presently accepted standards of care for the premature infant. Caloric intake was optimized as quickly as the infant would tolerate, with the aim of providing between $100-120 \mathrm{kcal} / \mathrm{kg} / \mathrm{day}$. The caloric density of the premature formula is $81 \mathrm{kcal} / \mathrm{dl}$; PTHM and fortified-PTHM have been estimated to contain 67 and $74 \mathrm{kcal} /$ dl, respectively. The premature formula contains approximately $95 \mathrm{mg}$ calcium/dl and $48 \mathrm{mg}$ phosphorus/dl. Forty percent of its fat content is medium-chain triglycerides. PTHM contains about $27 \mathrm{mg}$ calcium/dl and $14 \mathrm{mg}$ phosphorus/dl during the first 4-6 wk of lactation; thereafter, the content of both minerals decreases gradually (10). All infants were tube fed by intermittent (or bolus) gavage; a measured feeding volume being pushed from a plastic syringe through an indwelling nasogastric tube over about a 10 -min period. The nasogastric tube was changed daily. Vitamin supplements [0.5 ml Poly-vi-Sol/day (Mead Johnson Nutritional Division) and $0.5 \mathrm{ml}$ (25 IU) Aquasol E/day USV Pharmaceutical Corp., Tuckahoe, NY)] were given to all infants. Isolette temperature was maintained in the neutral thermal zone.

Vitamin D status was not evaluated, but each infant received 200 IU vitamin D/day from the multivitamin supplement. Since
Table 2. Isotopic abundance

\begin{tabular}{ccc}
\hline $\begin{array}{c}\text { Stable } \\
\text { isotopes } \\
\text { of calcium }\end{array}$ & $\begin{array}{c}\text { Natural } \\
\text { calcium } \\
\text { (atoms \%) }\end{array}$ & $\begin{array}{c}\text { Enriched } \\
\text { calcium* } \\
\text { (atoms \%) }\end{array}$ \\
\hline${ }^{40} \mathrm{Ca}$ & 96.90 & 59.06 \\
${ }^{42} \mathrm{Ca}$ & 0.65 & 0.60 \\
${ }^{43} \mathrm{Ca}$ & 0.14 & 0.14 \\
${ }^{44} \mathrm{Ca}$ & 2.08 & 3.71 \\
${ }^{46} \mathrm{Ca}$ & 0.003 & 34.91 \\
${ }^{48} \mathrm{Ca}$ & 0.19 & 1.58 \\
\hline
\end{tabular}

* Based on certified values provided by Oak Ridge Natural Laboratories.

its content in human milk is low (14), PTHM-fed infants received little additional vitamin $\mathrm{D}$. However, since the premature formula contained $50 \mathrm{IU}$ vitamin D/dl, fortified-PTHM- and formula-fed infants received an additional 40 and $75 \mathrm{IU} / \mathrm{kg} /$ day, respectively.

Preparation and administration of the stable isotope. Two $\mathrm{mg}$ of enriched calcium, as calcium carbonate $\left({ }^{46} \mathrm{CaCO}_{3}\right)$, with a 34.91 atoms \% enrichment of ${ }^{46} \mathrm{Ca}$ (Oak Ridge National Laboratory, Oak Ridge, TN) were dissolved in the smallest possible volume of reagent grade hydrochloric acid (37\%), and diluted to $50 \mathrm{ml}$ in a volumetric flask with deionized water (final $\mathrm{pH} \sim 3$ ). This solution had an elemental calcium concentration of $40 \mu \mathrm{g} /$ $\mathrm{ml}$ and a ${ }^{46} \mathrm{Ca}$ concentration of $13.96 \mu \mathrm{g} / \mathrm{ml}$. Table 2 compares the isotopic abundance in atoms \% of the stable calcium isotopes in natural calcium and the enriched calcium. At the time of stable isotope administration, a single accurately measured dose of this solution was administered via a nasogastric tube during one scheduled intermittent gavage feeding per study. After onehalf of the feeding volume had been given, the stable isotope solution was administered and then the feeding was finished. The dose of the stable isotope solution was $80 \mu \mathrm{g} \mathrm{Ca} / \mathrm{kg}(2.00$ $\mathrm{ml} / \mathrm{kg}$ ) for the premature formula-fed infants, $19.2 \mu \mathrm{g} \mathrm{Ca} / \mathrm{kg}$ $(0.48 \mathrm{ml} / \mathrm{kg})$ for PTHM-fed infants, and $49.6 \mu \mathrm{g} \mathrm{Ca} / \mathrm{kg}(1.24 \mathrm{ml} /$ $\mathrm{kg}$ ) for fortified-PTHM-fed infants.

Estimates of the total calcium and ${ }^{46} \mathrm{Ca}$ intake by the infants 
Table 3. Estimated total calcium and ${ }^{46} \mathrm{Ca}$ intake

\begin{tabular}{lccc}
\hline & $\begin{array}{c}\text { Premature } \\
\text { formula }\end{array}$ & PTHM & $\begin{array}{c}\text { Fortified } \\
\text { PTHM }\end{array}$ \\
\hline Average daily intake $(\mathrm{ml} / \mathrm{kg})$ & 150 & 164 & 158 \\
Dietary calcium intake $(\mathrm{mg} / \mathrm{kg} /$ & 142.50 & 44.28 & 96.38 \\
day) $\left(\mu \mathrm{g}{ }^{46} \mathrm{Ca} / \mathrm{kg} / \mathrm{day}\right)^{*}$ & $(5.39)$ & $(1.67)$ & $(3.64)$ \\
Dose of $\mathrm{enriched} \mathrm{Ca}(\mu \mathrm{g} / \mathrm{kg})(\mu \mathrm{g}$ & 80 & 19.2 & 49.6 \\
$\left.{ }^{46} \mathrm{Ca} / \mathrm{kg}\right)$ & $(27.93)$ & $(6.70)$ & $(17.32)$ \\
Total Ca intake $(\mathrm{mg} / \mathrm{kg} / \mathrm{day})(\mu \mathrm{g}$ & 142.58 & 44.30 & 96.40 \\
${ }^{46} \mathrm{Ca} / \mathrm{kg} /$ day $)$ & $(33.32)$ & $(8.37)$ & $(20.96)$ \\
$\%$ total Ca intake provided by & 0.056 & 0.043 & 0.051 \\
enriched Ca & & & \\
\hline
\end{tabular}

* $0.00378 \%$ (mass ratio) of naturally occurring calcium is ${ }^{46} \mathrm{Ca}$.

in each feeding group are shown in Table 3. These calculations are based on the average daily intake during the study period; a calcium content of $95 \mathrm{mg} / \mathrm{dl}$ for the premature formula and estimated at $27 \mathrm{mg} / \mathrm{dl}$ for PTHM (10) and $61 \mathrm{mg} / \mathrm{dl}$ for fortifiedPTHM; and the fact that $0.00378 \%$ (mass ratio) of calcium naturally occurs as ${ }^{46} \mathrm{Ca}$. Therefore, the stable isotope solution provided formula-fed infants with $0.056 \%$ of the total calcium intake on that day and achieved a 6.2-fold enrichment of dietary ${ }^{46} \mathrm{Ca}$. Similarly, the PTHM-fed infants received $0.043 \%$ of that day's total calcium intake as ${ }^{46} \mathrm{Ca}$ and a 5 -fold enrichment of dietary ${ }^{46} \mathrm{Ca}$, while the fortified-PTHM-fed infants received $0.051 \%$ of that day's total calcium intake as ${ }^{46} \mathrm{Ca}$ and a 5.8 -fold enrichment of dietary ${ }^{46} \mathrm{Ca}$. This degree of dietary stable isotope enrichment is adequate to insure sufficient analytical precision (21).

The stable isotope solution used in this project also contained enriched zinc $\left(65.51 \%\right.$ enrichment of $\left.{ }^{70} \mathrm{Zn}\right)$ for a multilabeling study. Measurements of dietary zinc absorption in these infants have been reported previously (11).

Experimental design and isotopic analysis. Determinations of dietary calcium absorption were performed as soon as the infant was gaining $10 \mathrm{~g} / \mathrm{kg} /$ day for 7 days and/or when a weight of about $1500 \mathrm{~g}$ was reached. Two $\mathrm{ml}$ of a $5 \%$ solution of carmine red $(100 \mathrm{mg})$ were used as a stool marker and were given by nasogastric tube at the start of the feeding in which the isotope solution was administered. A second dose of carmine red was administered $72 \mathrm{~h}$ after the first. Individual stools were collected from the time that the stable isotope solution was given until the second carmine red stool marker appeared. Stools were usually collected in a urine collection bag (U-Bag, Hollister, Inc., Chicago, IL) that was applied to each infant around the anus (33). After passage of a stool, the bag was removed, its opening was sealed, it was labeled and then stored at $-4^{\circ} \mathrm{C}$. A new bag was then applied to the perineum for collection of the next stool. Alternately, if the perianal area became irritated, individual stools were collected on a reversed plastic-lined diaper (37). Urine contamination of the stools was minimized by the use of 24-h urine collection bags (Hollister, Inc.).

Stools passed during the collection period were individually weighed, homogenized with deionized water, and frozen at $-70^{\circ}$ $\mathrm{C}$ until needed for radiochemical neutron activation analysis of fecal calcium isotopes as previously described in detail (21). Briefly, the stool homogenates were spiked with 85-strontium $\left({ }^{85} \mathrm{Sr}\right)$ radiotracer and then submitted to a series of chemical procedures that separated calcium from other constituents in the stool by precipitation with ammonium oxalate. The chemical yield of calcium with these procedures was determined by assessing the recovery of ${ }^{85} \mathrm{Sr}$. After preirradiation chemical separation, each sample (and the appropriate standard) was subjected to two-irradiation-decay-count cycles, as described previously (21). The first cycle is designed to measure ${ }^{48} \mathrm{Ca}$ content $\left[{ }^{48} \mathrm{Ca}\right.$ $\left.(\mathrm{n}, \gamma){ }^{49} \mathrm{Ca}: \mathrm{H}=8.72 \mathrm{~min} ; \gamma: 3084 \mathrm{Kev}\right]$; the second cycle ${ }^{46} \mathrm{Ca}$ content $\left[{ }^{46} \mathrm{Ca}(\mathrm{n}, \gamma){ }^{47} \mathrm{Ca}\left(\beta^{-}\right){ }^{47} \mathrm{Sc}: \mathrm{H}_{\mathrm{Ca}-47}=4.54\right.$ days; $\mathrm{H}_{\mathrm{S}-47}=$ 3.41 days; $\left.\gamma_{\mathrm{sc}-47}: 159 \mathrm{Kev}\right]$. Thus, the $\gamma$ rays at 3084 and 159 $\mathrm{Kev}$ are monitored employing a high-resolution gamma spec- trometry system (Canberra Industries, Model 8180, Meriden, CT).

In order to establish a correct fecal pooling protocol, the kinetics of ${ }^{46} \mathrm{Ca}$ excretion in feces were examined by analyzing sequential stools passed during three absorption studies in two infants. Although a good correlation was noted between the appearance of the first carmine red stool marker and the peak fecal enrichment of ${ }^{46} \mathrm{Ca}$, exclusion of the stools passed prior to the appearance of that stool marker might have tended to overestimate absorption. Therefore, values of fractional absorption of the ${ }^{46} \mathrm{Ca}$ dose were measured from a fecal pool prepared by combining all of the individually homogenized stools passed from the time that the stable isotope solution (and first carmine red marker) had been given until the second carmine red marker appeared in the stool, rather than from a pool of only those stools bracketed by the carmine red markers.

Calculation of calcium absorption. The concepts and analytical considerations that apply to stable isotope methods, especially to the fecal monitoring approach, have been previously described in detail $(23,25-27)$. Since stable isotopes are present in all natural materials as a normal component of minerals, their contributions from all unenriched sources of fecal isotopic content must be measured accurately and subtracted from the total measured quantity of the stable isotope in the fecal pool. Therefore, as shown in the scheme in Figure 1, when ${ }^{46} \mathrm{Ca}$ is used as an extrinsic tag, the ${ }^{46} \mathrm{Ca}$ that is found in the fecal pool will have originated from the unabsorbed fraction of the administered stable isotope dose, the unabsorbed fraction of dietary calcium, unabsorbed endogenous calcium secretions, and any source of calcium contamination during handling. Since the isotopic ratio for ${ }^{46} \mathrm{Ca} /{ }^{48} \mathrm{Ca}$ is constant and equal to the natural ratio for all fecal sources of calcium, except that from the extrinsic tag, the fecal content of ${ }^{46} \mathrm{Ca}$ originating from the tag can readily be calculated as the difference between total fecal ${ }^{46} \mathrm{Ca}$ and that originating from all unenriched sources. Absorption of the tag is then calculated as the difference between intake and fecal output. Thus, the expression for calculating the fractional absorption $(F)$ of the ${ }^{46} \mathrm{Ca}$ dose is given by the following equation:

$$
\mathrm{F}=\frac{\mathrm{A}_{0,46 \mathrm{Ca}}^{*}-\left(\mathrm{A}_{\mathrm{f}, 46 \mathrm{Ca}}-\mathrm{R} \times \mathrm{A}_{\mathrm{f}, 48 \mathrm{Ca}}\right)}{\mathrm{A}_{0,46 \mathrm{Ca}}^{*}}
$$

where $\mathrm{A}_{0,46 \mathrm{Ca}}^{*}=$ amount of ${ }^{46} \mathrm{Ca}$ in the administered dose of the stable isotope solution;

$$
\mathrm{A}_{\mathrm{f},{ }^{46} \mathrm{Ca}}=\text { the total amount of }{ }^{46} \mathrm{Ca} \text { in the fecal pool; }
$$

$\mathrm{R}=$ the mass isotopic ratio of ${ }^{46} \mathrm{Ca} /{ }^{48} \mathrm{Ca}$ for natural calcium and is 0.0171.(0.00378:0.221); and $\mathrm{A}_{\mathrm{f}}{ }^{48} \mathrm{Ca}=$ the total amount of ${ }^{48} \mathrm{Ca}$ in the fecal pool.

Note that the expression

$$
\mathrm{A}_{\mathrm{f},{ }^{46} \mathrm{Ca}}-\mathrm{R} \times \mathrm{A}_{\mathrm{f},{ }^{48} \mathrm{Ca}}=\mathrm{A}_{\mathrm{f},{ }^{46} \mathrm{Ca}}^{*}
$$

since $R \times A_{f, 48}$ equals that portion of the total fecal ${ }^{46} \mathrm{Ca}$ that is derived from a sum of the unabsorbed fractions of dietary ${ }^{46} \mathrm{Ca}$ and endogenous ${ }^{46} \mathrm{Ca}$ secretion, and the remainder corresponds to the fecal content of the ${ }^{46} \mathrm{Ca}$ from the administered dose of the stable isotope solution.

\section{RESULTS}

Kinetics of ${ }^{46} \mathrm{Ca}$ excretion in feces. The kinetics of excretion of the administered ${ }^{46} \mathrm{Ca}$ dose were examined in sequential stools passed during three absorption studies. The stools were collected from the time that the stable isotope solution was given until the second carmine red marker appeared in the stool. Each stool was analyzed for ${ }^{46} \mathrm{Ca}$ and ${ }^{48} \mathrm{Ca}$, a mass isotope ratio, ${ }^{46} \mathrm{Ca} /{ }^{48} \mathrm{Ca}$, was calculated, and the percent of the administered dose in the stool sample was determined. Figure 2 displays the cumulative fecal excretion (\%) of the administered ${ }^{46} \mathrm{Ca}$ dose as a function of time for three studies in two premature formula-fed infants. One infant (1) was studied at 15 days of age when she weighed 1100 


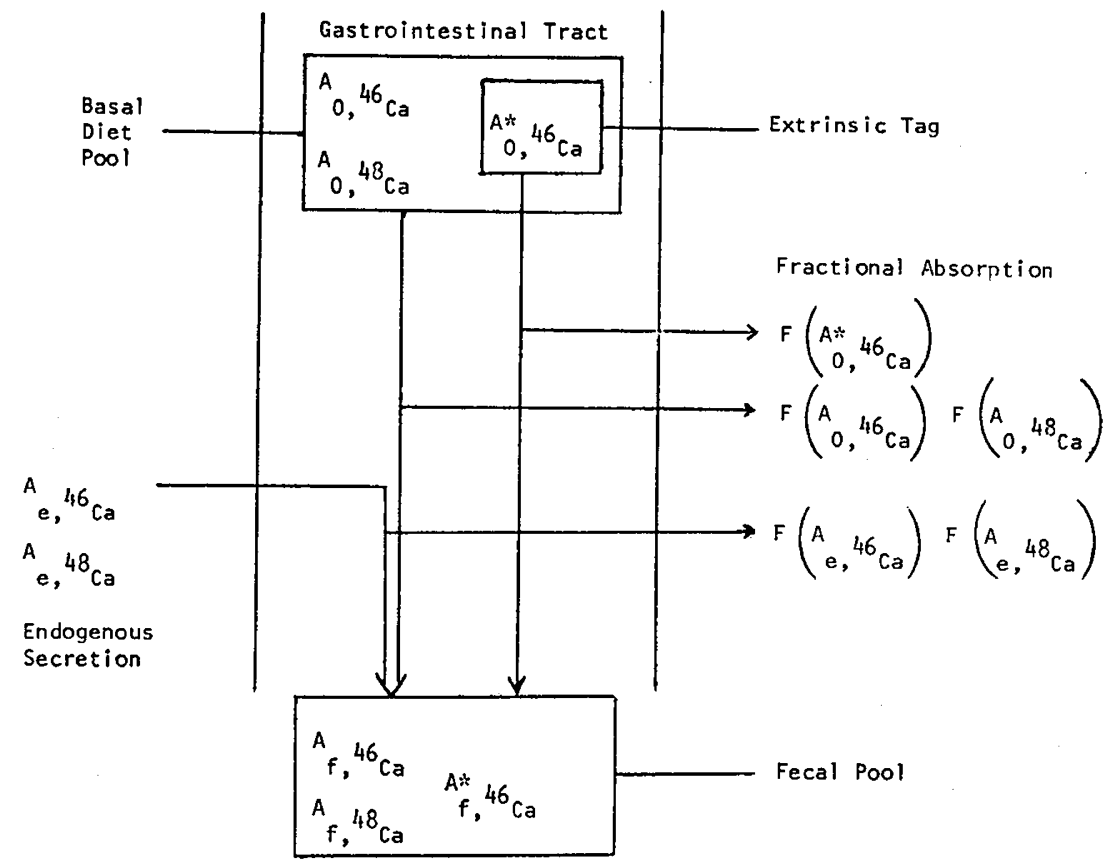

Fig. 1. Scheme of calcium absorption and secretion into the gastrointestinal tract. Symbols are as follows: $A_{O, C a}$ is the dietary content of the specified stable isotope of calcium; $A_{e, C a}$ is the endogenous contribution of the specified calcium isotope; $A_{f, C a}$ is the fecal content of the specified calcium isotope; and $F\left(A_{O, C a}\right)$ refers to the fractional absorption of the specified calcium isotope. The asterisk indicates the enriched isotope. See text for additional explanation.

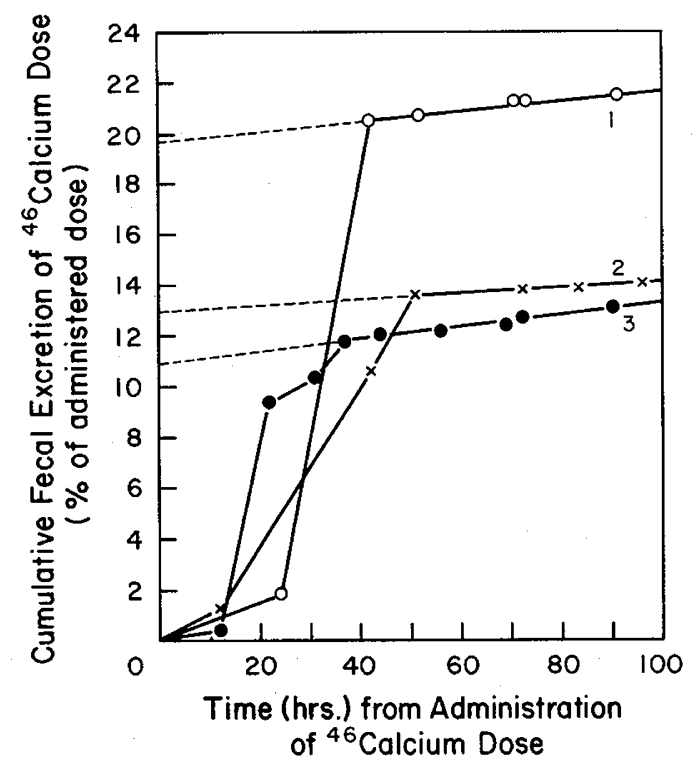

Fig. 2. The cumulative fecal excretion (\%) of the ${ }^{46} \mathrm{Ca}$ dose is displayed as a function of time for three studies in two premature formulafed infants. One infant (1) was studied at 15 days of age when she weighed $1000 \mathrm{~g}$. The other infant was studied at 23 and at 37 days of age, when he weighed $1300 \mathrm{~g} \mathrm{(2)}$ and $1550 \mathrm{~g}(3)$, respectively. Note that a collection period of $50 \mathrm{~h}$ from administration of ${ }^{46} \mathrm{Ca}$ appears sufficient for complete collection of the unabsorbed isotope. Linear extrapolation to zero transit time for the second phase of the excretion curve corrects for reentry of ${ }^{46} \mathrm{Ca}\left[(1) \mathrm{Y}=19.703+0.02039 \mathrm{X}, \mathrm{r}^{2}=0.984 ;(2) \mathrm{Y}=12.948+0.01161 \mathrm{X}\right.$, $\left.r^{2}=0.796 ;(3) Y=10.9594+0.02280 X, r^{2}=0.955\right]$. See text for additional discussion.

g. The other was studied at 23 and at 37 days of age, when he weighed $1300 \mathrm{~g} \mathrm{(2)}$ and $1550 \mathrm{~g}(3)$, respectively. This analysis demonstrated that a collection period of about $50 \mathrm{~h}$ from administration of the stable isotope dose was sufficient for a complete collection of unabsorbed isotope. The positive slope in the cumulative fecal excretion curve is assumed to result from reentry of absorbed ${ }^{46} \mathrm{Ca}$ into the gastrointestinal tract, and amounts to about $0.5 \%$ of the administered dose per 24 -h period. The significance of neglecting reentry of the absorbed dose during the fecal collection period was determined by comparing the fractional absorption calculated by two methods. The first method (28), and the one illustrated in Figure 2 , requires ${ }^{46} \mathrm{Ca}$ and ${ }^{48} \mathrm{Ca}$ analyses of individual stools from administration of the ${ }^{46} \mathrm{Ca}$ dose until sufficient data points past the excretion of the unabsorbed dose have been obtained, so that a suitable linear regression analysis can be applied to determine true fecal excretion at the time of actual absorption. The second method is based on analysis of the ${ }^{46} \mathrm{Ca} /{ }^{48} \mathrm{Ca}$ mass ratio in single, pooled stool collection. The comparison showed that measurements from a single, pooled stool collection consistently underestimated the absorption value calculated with linear extrapolation by about $2 \% ; 78.5$ versus $80.3 \%, 86.0$ versus $87.1 \%$, and 86.9 versus $89.0 \%$. However, analysis of the pooled stool collection was believed to be sufficiently accurate for estimation of true calcium absorption. Therefore, that method was utilized in the 13 remaining studies, and a fecal pool was prepared by combining the individually homogenized stools collected from the time that the stable isotope solution was given until the second carmine red stool marker was passed.

Comparative aspects of calcium absorption. In addition to providing details about the age, body weight, and diet of each of the 13 infants at the time of the determination of calcium absorption, Table 1 also lists the fractional absorption of the ${ }^{46} \mathrm{Ca}$ dose for each infant. Figures 3-6 display each of these values in relation to the infant's diet and to the postnatal age, postconceptual age, and body weight, respectively, at the onset of the determination of calcium absorption. Visual inspection of these scattergrams demonstrates that the fractional absorption of the ${ }^{46} \mathrm{Ca}$ dose was not apparently related to those factors. Furthermore, although the mean fractional absorption of ${ }^{46} \mathrm{Ca}$ in the PTHM-fed infants was slightly higher than that of either the fortified-PTHM-fed or premature formula-fed infants $(89.6 \pm$ $2.2 \%$ versus $80.8 \pm 6.0 \%$ and $82.7 \pm 3.4 \%$, respectively), no statistically significant differences in the fractional absorption of ${ }^{46} \mathrm{Ca}$ were found between any two of the diets. Combining these values results in a fractional absorption of ${ }^{46} \mathrm{Ca}$ of $84.4 \pm 2.2 \%$. 


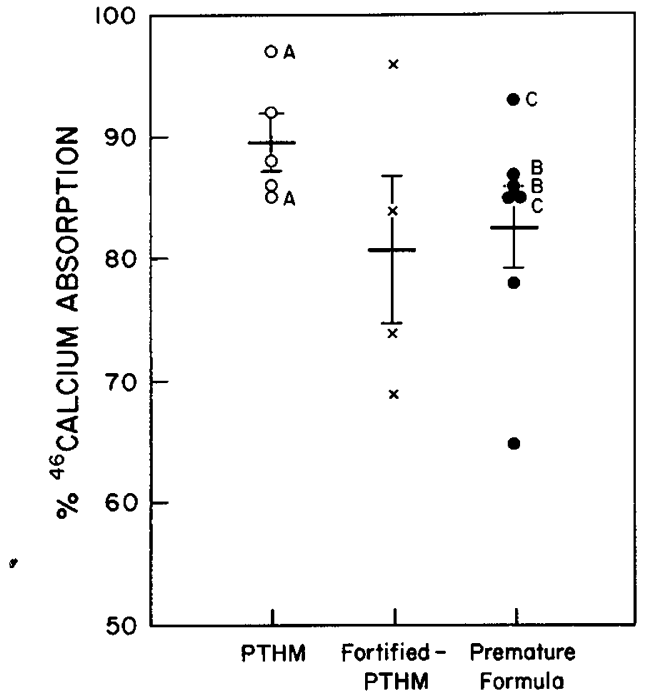

Fig. 3. The value of the fractional absorption of the ${ }^{46} \mathrm{Ca}$ dose for each study (see Table 1) is displayed in relation to the infant's diet. $A, B$, and $C$ refer to the infants studied twice (see Table 1). Bars represent mean $\pm \mathrm{SE}$.

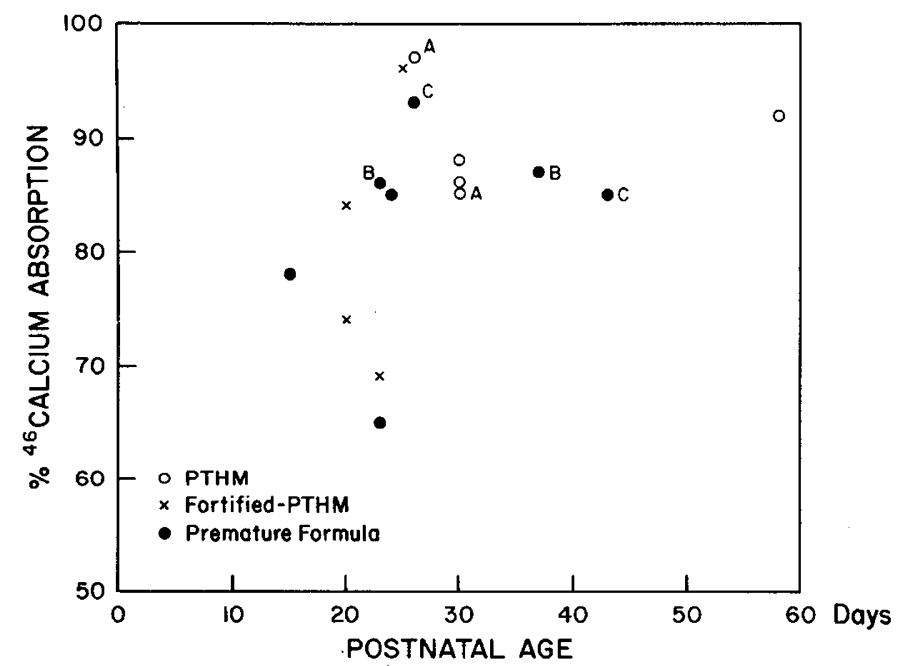

Fig. 4. The value of the fractional absorption of the ${ }^{46} \mathrm{Ca}$ dose for each study (see Table 1 ) is displayed in relation to the infant's diet and postnatal age at the time of the study. $A, B$, and $C$ refer to the infants studied twice (see Table 1).

Therefore, if absorption of the ${ }^{46} \mathrm{Ca}$ dose reflects absorption of dietary calcium, about $80 \%$ of dietary calcium is absorbed.

\section{DISCUSSION}

Although the calcium content of mature human milk has been used to define the minimum recommended level of dietary calcium for growing premature infants (3), calcium requirements for such infants have often been based on estimates of the intrauterine calcium accretion rate and measurements of net calcium absorption and retention $(2,3,31,32,41)$. Corresponding to the exponential increase in fetal body weight from about 600-2500 g between 24-36 wk of gestation, an exponential rise in total fetal calcium and in the daily increment of calcium accumulation have been described $(2,15,31,32,38,41,42)$. Total body calcium increases from about 4 to $30 \mathrm{~g}$ during the 3 rd trimester, while the daily calcium accretion rate increases from about 60 to more than $300 \mathrm{mg}$ and the body concentration of calcium from about 650 to more than $800 \mathrm{mg} / 100 \mathrm{~g}$ body weight $(2,15,31,32,38,41,42)$. Correcting the daily calcium accumulation rate for fetal body weight results in values ranging

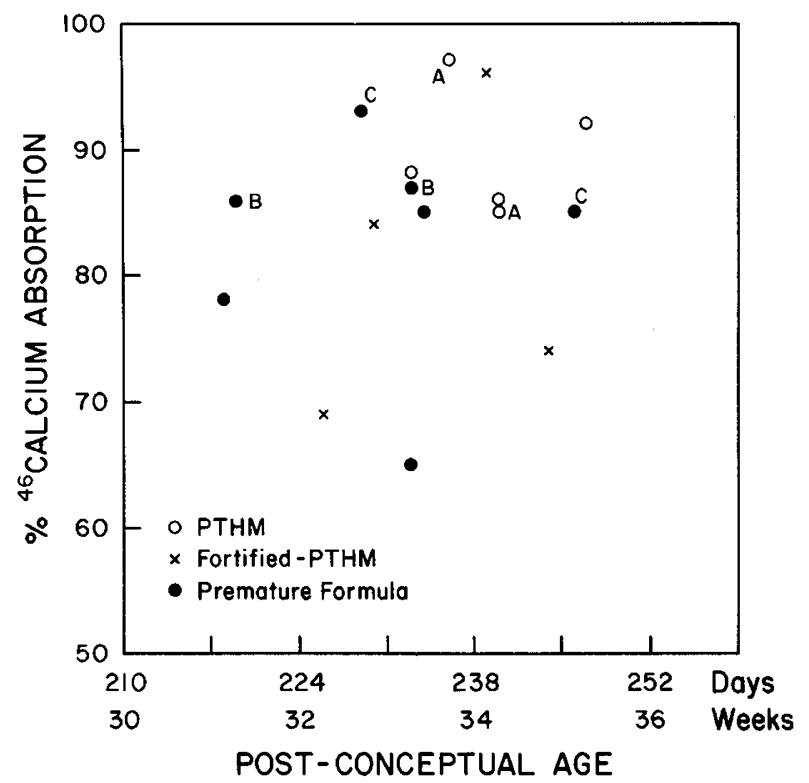

Fig. 5. The value of the fractional absorption of the ${ }^{46} \mathrm{Ca}$ dose for each study (see Table 1) is displayed in relation to the infant's diet and postconceptual age at the time of the study. $A, B$, and $C$ refer to the infants studied twice (see Table 1).

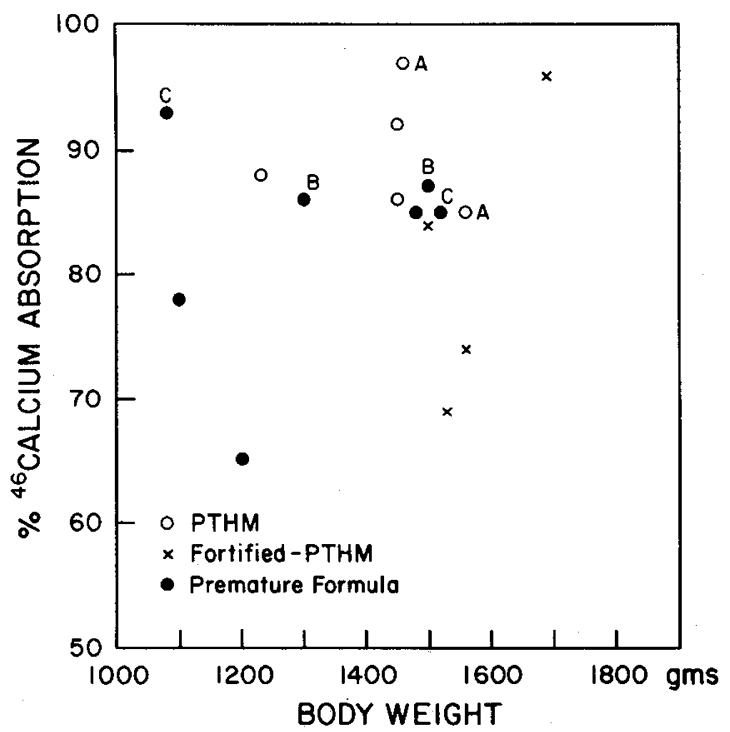

Fig. 6. The value of the fractional absorption of the ${ }^{46} \mathrm{Ca}$ dose for each study (see Table 1) is displayed in relation to the infant's diet and body weight at the time of the study. $A, B$, and $C$ refer to the infants studied twice (see Table 1).

from about $120-150 \mathrm{mg} / \mathrm{kg} /$ day during this gestational interval $(2,31,32,41)$. Since the goal of nutrition for premature infants is to provide a diet that permits growth, and presumably nutrient retention, at a rate that approximates intrauterine weight gain and nutrient accretion during the 3rd trimester, this range for calcium accumulation has been used as the standard with which to evaluate the adequacy of feeding regimens $(2,3,31,32,41)$.

Intestinal calcium uptake is considered the sum of two mechanisms $(1,40)$. The first is an active, carrier-mediated process which appears to be dependent on 1,25 $(\mathrm{OH})$-vitamin $\mathrm{D}_{3}$ and involves calcium-binding protein. The second is passive diffusion. Although these mechanisms have not been studied in infants, Younoszai (40) extrapolated the findings from in vivo perfusion studies performed in developing rats to human infants, and suggested that passive diffusion would be the dominant calcium absorptive process in the neonate, especially the premature neonate. This conclusion was consistent with the linear 
relationship between dietary calcium intake and net calcium absorption that has been observed in studies with human infants.

Net or apparent calcium absorption has been shown to be influenced by a number of factors, including postconceptual age, the efficiency of fat absorption, the dietary source of calcium, and the dietary content of calcium, phosphorus, vitamin D and other components such as phytate, lactose, medium- and longchain triglycerides $(1,2,4)$. These factors may account for values of net calcium absorption ranging from $24-80 \%$ of intake that have been reported from calcium balance studies performed in growing premature infants fed pooled banked mature milk $(30$ $31,39)$, their own mother's PTHM $(5,29)$, modified cow's milk formulas designed for term infants $(5,9,29,31,35)$, or formulas specially designed to meet the nutritional needs of growing premature infants $(18,33)$.

However, these values for calcium absorption have been obtained with standard metabolic balance methodology, which is based on determinations of intake and fecal excretion and does not measure endogenous secretion. Thus, it only provides a measure of net balance across the intestinal tract, and tends to underestimate true dietary calcium absorption $(2,25,28)$. In addition, nonrandom collection errors and irregularities in fecal excretion tend to increase variability in the results $(2,25)$. In contrast, the stable isotope tracer method permits an accurate assessment of true absorption $(25,26)$. Barltrop et al. (7) have utilized this method to study calcium absorption and endogenous fecal excretion of calcium in formula-fed premature infants, and found that calcium absorption averaged $36 \%$ and remained constant while calcium intake rose from about $200-500 \mathrm{mg} / \mathrm{dl}$ (about $100-250 \mathrm{mg} / \mathrm{kg} /$ day). We (11) have previously demonstrated the suitability of this methodology in a study of dietary zinc absorption in the premature infants described herein.

Stable isotope tracer methodology uses naturally occurring, nonradioactive tracers to enrich the diet with a given stable isotope of the mineral of interest $(25,26)$. The theory and assumptions underlying these methods have been reviewed in detail $(6,25,26,28)$. The principle assumption is that absorption of the stable isotope tracer, or extrinsic tag, takes place from a common dietary pool, and thus, that the fractional absorption of the tracer will be the same as the natural mineral. The validity of this assumption appears to hold for zinc $(13,20)$ and iron (16) but may not hold for selenium (8). As previously demonstrated by Barltrop et al. (7), our data indicate that the extrinsic tag approach can be utilized to examine the absorption of calcium in growing premature infants. Although a stool collection period of about $50 \mathrm{~h}$ following the administration of the stable isotope solution appeared to be sufficient for a complete collection of the unabsorbed isotope and determination of fractional ${ }^{46} \mathrm{Ca}$ absorption, stools were pooled from the time that the stable isotope solution was given until the stool marker administered $72 \mathrm{~h}$ later was passed. This pooling protocol was selected because it is known that underpooling (i.e. pooling an incomplete stool collection) overestimates absorption, while limited overpooling (i.e. pooling a stool collection that clearly includes all unabsorbed stable isotope) introduces no significant analytical error $(25,26)$. Unfortunately, this fecal pool slightly underestimated ${ }^{46} \mathrm{Ca}$ absorption since it included about $0.5 \%$ of the administered isotope dose per 24-h period that reentered or was resecreted into the gastrointestinal tract. Such resecretion occurs as part of endogenous fecal calcium, but initially contains an increased content of ${ }^{46} \mathrm{Ca}$ because of elevated blood levels of the tracer (28). However, reentry of the absorbed ${ }^{46} \mathrm{Ca}$ cannot be used to quantitate endogenous calcium secretions because isotopic equilibration into the body pools responsible for endogenous secretion requires a greater length of time. Furthermore, since analysis of a single, pooled stool collection resulted in an error that was only about $2 \%$ of the true absorption, we believed that determination of ${ }^{46} \mathrm{Ca}$ absorption from a single pool was sufficiently accurate. Additionally, we recognize that the extrinsic tag methodology used in this investigation is not immune from the nonrandom errors that occur in standard metabolic balance studies $(2,25)$.
Although the use of the extrinsic tag approach permits the calculation of endogenous calcium secretion (25-28), adequate steps to insure an accurate determination of calcium balance and to permit this calculation were not taken in the design and performance of this investigation. Barltrop et al. (7) reported mean endogenous fecal calcium excretion to be $70-89 \mathrm{mg} /$ day (approximately $35-45 \mathrm{mg} / \mathrm{kg} / \mathrm{day}$ ), to be largely independent of calcium intake, and to be characteristic of an individual infant, but highly variable among infants (ranging from 4-150 mg/day). Endogenous fecal calcium secretion has been shown to be relatively constant for a large adult population; it is independent of diet and disease and averages $130 \mathrm{mg} /$ day (17).

This project evaluated the effect of diet, postnatal age, postconceptual age, and body weight on the absorption of dietary calcium. As evident in Table 1 and Figures 3-6, absorption of the ${ }^{46} \mathrm{Ca}$ dose did not seem clearly influenced by any of these factors, and overall, averaged $84.4 \pm 2.2 \%$. However, since the ${ }^{46} \mathrm{Ca}$ dose did not equilibrate with the feeding prior to its administration, but was given directly into the stomach within the midst of a feeding, there may not have been adequate mixing of the ${ }^{46} \mathrm{Ca}$ dose with dietary calcium. Thus, some of the enriched calcium may have been absorbed as if from a clear solution rather than as part of the common dietary pool, yielding artificially high values. Nonetheless, net calcium absorption as determined with standard metabolic balance methods has been quite variable. Although it has ranged from $24-80 \%(5,9,18,29,30,31,33$, 35,39 ), several recent studies with formulas designed for growing premature infants $(18,33)$ and PTHM $(29)$ have reported net calcium absorption values of 66-80\%, values comparable to our findings. However, our data did not confirm Shaw's results (31). He performed serial metabolic balances during the first 60-70 days after birth, and observed that two important determinants of the net amount of calcium absorbed were the length of gestation and the postnatal age of the infants, with this difference being most pronounced after the 30th postnatal day of life. Unfortunately, since only three of our studies were performed after 30 days of age, any effect of increasing maturity, i.e. with increasing postnatal age, postconceptual age, and body weight (Figs. 4-6), is difficult to discern.

Finally, this study did not specifically investigate the effect of dietary calcium content or the role of vitamin D, efficiency of fat absorption, or medium-chain triglycerides on calcium absorption. Dietary calcium intake ranged from about 45 to $142 \mathrm{mg} /$ $\mathrm{kg}$ /day (Table 3), and the calcium/phosphorus ratio remained about 2:1 with each type of feeding. Vitamin D status was not evaluated, but each infant received at least $200 \mathrm{IU}$ vitamin D/ day. Although not performed as part of this study, we have found that fat absorption from PTHM, this premature formula, and PTHM fortified with this formula to be approximately $90 \%(12$, Ehrenkranz, RA, unpublished data). As noted above, $40 \%$ of the fat content of the premature formula is medium-chain triglycerides.

In conclusion, we have utilized the extrinsic tag approach with stable isotope methodology in the study of dietary calcium absorption in growing premature infants. Our findings suggest, that under the experimental conditions of this study, about $80 \%$ of dietary calcium is absorbed and that diet, postnatal and postconceptual age, and body weight may exert little influence. We believe that this methodology can be used to examine the absorption of other dietary minerals in growing premature infants and in older infants.

Acknowledgments. The authors thank Ms. Debra Camputaro for her assistance in preparing the manuscript and the nurses of the NBSCU for their assistance during this investigation.

\section{REFERENCES}

1. Allen LH 1982 Calcium bioavailability and absorption: a review. Am J Clin Nutr 35:783

2. American Academy of Pediatrics Committee on Nutrition 1978 Calcium requirements in infancy and childhood. Pediatrics 62:826

3. American Academy of Pediatrics Committee on Nutrition 1977 Nutritional 
needs of low-birth-weight infants. Pediatrics 60:519

4. Atkinson SA 1983 Calcium and phosphorus requirements of low-birth-weight infants: a nutritional and endocrinological perspective. Nutr Rev 41:69

5. Atkinson SA, Radde IC, Anderson GH 1983 Macromineral balances in premature infants fed their own mother's milk or formula. J Pediatr 102:99

6. Aubert J-P, Bronner F, Richelle LJ 1963 Quantitation of calcium metabolism. Theory. Theory J Clin Invest 42:885

7. Barltrop D, Mole RH, Sutton A 1977 Absorption and endogenous faeca excretion of calcium by low birthweight infants on feeds with varying contents of calcium and phosphate. Arch Dis Child 52:41

8. Christensen MJ, Janghorbani M, Steinke FH, Istfan NW, Young VR 1983 Simultaneous determination of absorption of selenium from poultry meat and selenite in young men: application of a triple stable isotope method. $\mathrm{Br}$ J Nutr 50: 43

9. Day GM, Chance GW, Radde IC, Reilly BJ, Park E, Sheepers J 1975 Growth and mineral metabolism in very low birth weight infants. II. Effects of calcium supplementation on growth and divalent cations. Pediatr Res 9:568

10. Ehrenkranz RA, Ackerman BA, Nelli CM 1984 Calcium (Ca), phosphorus (P) zinc $(\mathrm{ZN})$, and copper $(\mathrm{Cu})$ content of preterm human milk. Pediatr Res 18:195A

11. Ehrenkranz RA, Ackerman BA, Nelli CM, Janghorbani M 1984 Determination of the dietary bioavailability of zinc in premature infants with stable isotopes. Am J Clin Nutr 40:72

12. Ehrenkranz RA, Chamberlin MA, Gettner PA, Nelli CM 1984 Nutritiona adequacy of fortified preterm human milk (PTHM) in VLBW infants. Pediatr Res 18:195A

13. Evans GW, Johnson PE 1977 Determination of zinc availability in foods by the extrinsic label technique. Am J Clin Nutr 30:873

14. Fomon SJ, Filer LJ Jr 1976 Milks and formulas. In: Fomon SJ (ed) Infant Nutrition, WB Saunders, Philadelphia, pp 359-407

15. Forbes GB 1976 Calcium accumulation by the human fetus. Pediatrics $57: 976$

16. Halbert L 1981 Bioavailability of dietary iron in man. Ann Rev Nutr 1:123

17. Heaney RP, Skillman TG 1964 Secretion and excretion of calcium by the human gastrointestinal tract. J Lab Clin Med 64:29

18. Huston RK, Reynolds JW, Jensen C, Buist NRM 1983 Nutrient and mineral retention and vitamin $D$ absorption in low-birth-weight infants: effect of medium-chain triglycerides. Pediatrics 72:44

19. Janghorbani M, Christensen MJ, Nahapetian A, Young VR 1982 Selenium metabolism in healthy adults: quantitative aspects using the stable isotope ${ }^{74} \mathrm{SeO}_{3}{ }^{2}$. Am J Clin Nutr 35:647

20. Janghorbani M, Istfan NW, Pagounes J; Steinke FH, Young VR 1982 Absorption of dietary zinc in man: Comparison of intrinsic and extrinsic labels using a triple stable isotope method. Am J Clin Nutr 36:537

21. Janghorbani M, Sundaresan A, Young VR 1981 Accurate measurement of stable isotopes ${ }^{46} \mathrm{Ca}$ and ${ }^{48} \mathrm{Ca}$ in human feces, plasma, and urine in relation to human nutrition and calcium. Clin Chim Acta 113:267

22. Janghorbani M, Ting BTG, Young VR 1980 Absorption of iron in young men studied by monitoring excretion of a stable iron isotope $\left({ }^{58} \mathrm{Fe}\right)$ in feces. $J$ Nutr 110:2190

23. Janghorbani M, Ting BTG, Young VR 1980 Accurate analysis of stable isotopes ${ }^{68} \mathrm{Zn},{ }^{70} \mathrm{Zn}$, and ${ }^{58} \mathrm{Fe}$ in human feces with neutron activation analysis.
Clin Chim Acta 108:9

24. Janghorbani M, Ting BTG, Young VR 1981 Use of stable isotopes of selenium in human metabolic studies: development of analytical methodology. Am J Clin Nutr 34:2816

25. Janghorbani M, Young VR 1980 Stable isotope methods for bioavailability assessment of dietary minerals in humans. Adv Nutr Res 3:127

26. Janghorbani M, Young VR 1980 Use of stable isotopes to determine bioavailability of minerals in human diets using the method of fecal monitoring. Am J Clin Nutr 33:2021

27. Janghorbani M, Young VR 1983 Stable isotope approaches for measurement of dietary zinc availability in man. In: Inglett GE (ed) Am Chem Soc Symp Series 210 American Chemical Society, Washington DC, pp 41-59

28. Lutwak L 1969 Tracer studies of intestinal calcium absorption in man. Am J Clin Nutr 22:771

29. Rowe J, Rowe D, Horak E, Spackman T, Saltzman R, Robinson S, Philipps A, Raye J 1984 Hypophosphatemia and hypercalciuria in small premature infants fed human milk: evidence for inadequate dietary phosphorus. J Pediatr 104:112

30. Senterre J, Putet G, Salle B, Rigo J 1983 Effects of vitamin D and phosphorus supplementation on calcium retention in preterm infants fed banked human milk. J Pediatr 103:305

31. Shaw JCL 1976 Evidence for defective skeletal mineralization in low birthweight infants: the absorption of calcium and fat. Pediatrics 57:16

32. Shaw JCL 1973 Parenteral nutrition in the management of sick low birthweight infants. Pediatr Clin North Am 20:333

33. Shenai JP, Reynolds JW, Babson SG 1980 Nutritional balance studies in verylow-birth-weight infants: Enhanced nutrient retention rates by an experimental formula. Pediatrics 66:233

34. Steichen JJ, Gratton TL, Tsang RC 1980 Osteopenia of prematurity: the cause and possible treatment. J Pediatr $96: 528$

35. Tantibhedhyangkul $P$, Hashim SA 1978 Medium-chain triglyceride feeding in premature infants: effects on calcium and magnesium absorption. Pediatrics 61:537

36. Ting BTG, Kasper LJ, Young VR, Janghorbani M 1984 Copper absorption in healthy young men: Studies with stable isotope ${ }^{65} \mathrm{Cu}$ and neutron activation analysis. Nutr Res 4:757

37. Watkins JB, Bliss CM, Donaldson RM Jr, Lester R 1974 Characterization of newborn fecal lipid. Pediatrics 53:511

38. Widdowson EM, Spray CM 1951 Chemical development in utero. Arch Dis Child 26:205

39. Williamson S, Finucane E, Ellis H, Gamsu HR 1978 Effect of heat treatment of human milk on absorption of nitrogen, fat, sodium, calcium, and phosphorus by preterm infants. Arch Dis Child 53:555

40. Younoszai MK 1981 Development of intestinal calcium transport. In: Lebenthal E (ed) Textbook of Gastroenterology and Nutrition in Infancy. Raven Press, New York, pp 623-629

41. Ziegler EE, Biga RL, Fomon SJ 1981 Nutritional requirements of the premature infant. In: Suskind RM (ed) Textbook of Pediatric Nutrition. Raven Press, New York, pp 29-39

42. Ziegler EE, O'Donnell AM, Nelson SE, Fomon SJ 1976 Body composition of the reference fetus. Growth 40:329 